\title{
The Compatibility and Implementation Path of Technical, Literary, Ideological and Political Education of English Listening and Speaking Courses
}

\author{
LI Liangjia \\ School of Foreign Languages, Jishou University, China
}

To cite this article: LI Liangjia. (2021). The Compatibility and Implementation Path of Technical, Literary, Ideological and Political Education of English Listening and Speaking Courses. Asia-Pacific Journal of Humanities and Social Sciences, 01:3, 124130, DOI: 10.53789/j.1653-0465.2021.0103.013.p

To link to this article: https: //doi.org/10.53789/ j.1653-0465.2021.0103.013.p

This article is the result of the project entitled "Teaching Mode of English teaching and: English Listening Training in the Wuling Mountain Areas" ( Grant No. 18C0564) supported by Hunan Provincial Department of Education

Abstract: The English Listening and Speaking Courses are essential for cultivating English majors. In the professional course study, Western culture will have a specific impact on students' cultural attitudes; it is necessary to incorporate ideological and political education into the listening and speaking courses to give full play to its education function and prevent biased listening and believing. The introduction of critical multi-perspectives helps students form a correct outlook on the world, life, and values. As the carrier of culture, English listening and speaking courses carry people's ideas, world outlook, outlook on life, values, etc. Skill and literature should not be isolated and separated, and teachers should strive to achieve an organic combination. The realization of its multi-dimensional curriculum goals and paths is related to the two-way international cultural interaction, the explicit and implicit ideological and political teaching, the practical and testing classrooms, and the balanced input and output of literary audio-visual materials in the new media environment. Keywords: International Cultural Communication; English Listening and Speaking Course; Ideology and Politics; skills Training

Notes on the contributor: LI Liangiia is a lecturer in the School of Foreign Languages, Jishou University. His academic interest lies in Foreign Literature and Culture, and Movie Studies.

\section{英語聽說課程技能性、文學性、 思政性的契合與實現路徑}

\author{
李良嘉 \\ 吉首大學外國語學院
}

摘 要: 英語聽說課程是培飬英語專業人才的骨幹技能課程。專業課程學習中, 西方文化對於學 生的文化觀念會造成一定的影響; 有必要在聽說課程中融入思想政治教育, 發揮其育人功能, 防止 
偏聽偏信。批判性多視角的引入幫助學生形成正確的世界觀、人生觀和價值觀。英語聽說課程, 作為文化的載體, 承載著人的思想理念、世界觀、人生觀、價值觀等; 技能性、文學性、思政不應是孤 立分開的,教學應該努力實現三者的有機結合。其多維課程目標和路徑的實現和契合, 在新媒體 環境下, 與隻向的國際文化互動、顯隱性思政教學、實戰檢驗性課堂、文學性視聽材料的平衡性輸 入輸出等有關。

關鍵词: 國際文化傳播; 英語聽說課程; 思政; 技能訓練

基金項目: 本文為湖南省教育廳—般項目系列成果“武陵山區的英語專業教學和慕課化實踐— 口譯法英語聽記實訓教學模式”, 立項編號 18C0564。

\section{引言}

課程思政是英語專業課程建設、教育教學的有機組成部分。賦予了專業課程引領人文價值的重任, 為 新時代國際化綜合人才培養, 提供了正確的導向。高校英語課程是人文性和工具性的讋證統一:不僅要教 授學生英語語言基礎知識, 培養和提高學生基本語言能力; 更應該以人為本, 注重人文綜合素質的培養和全 面發展。學生通過英語類技能課程的學習, 掌握、運用語言交際工具, 同時提升人文素養, 強化信念擔當。 實現全面習近平總書記在十九大報告中指出的“文化是一個國家、一個民族的靈魂。文化興國運興, 文化強 民族強。沒有高度的文化自信, 沒有文化的繁榮興盛, 就沒有中華民族偉大復興。”

\section{一、聽說課程思政必要性與顯性、隱性思政}

外語專業的大學生身處多元文化碰撞和變革的前沿,豐富的世界文本提供了更多的“他者”話語體系; 飽含西方價值觀的英美文化也充滿著與東方文明古國不同的知識體系、話語體系、價值體系: 個人主義、物 質主義、演講辯論的議會政治等。外語專業課程思政的一個初心,應該就是拿來主義,學習借箽的同時又不 能喪失民族立場, 因此批判性借鑒學習很重要。英語聽說課程思政, 關乎民族地區高校英語教育培養什麼 接班人。長遠來看, 是維護民族地區社會穩定、實現國家長治久安的需要。外語教學中強調“多維目標”,即 課堂教學要達成三個目標維度: 情感態度和價值觀、過程和方法、知識與技能; 或者是基於其上的衍生複合 體。這三個目標很難用孤立的方法或者手段來實現,但幾個緧藏其中的基本原則卻是必需: 多元互觀 (批判 性), 過程中的顯隱性思政(潜移默化)，和實踐、實戰技能培養( 检验性)。

\section{（一）本土與他者互觀 ( 批判性)}

高校英語聽說課程是培養英語人才的重要途徑。在專業課程學習過程中,西方文化對於學生的文化觀 念會造成一定的影響, 有必要在英語課程教學過程中融人思想政治教育, 發揮其育人功能的需要, 以批判的 視角幫助學生形成正確的世界觀、人生觀和價值觀, 其本質也是情感態度和價值觀的多元化塑造。作為文 化的載體, 也有人文性, 承載著人的思想理念、世界觀、人生觀、價值觀等。其工具性和人文性不是孤立分開 的,教學應該努力實現兩者的有機結合。顯性的思政教育和隱形的潛移默化的思政教育,都是必要的,其路 
Asia-Pacific Journal of Humanities and Social Sciences

徑更加值得思考。習總書記關於人類共同命運體、民族文化的共同精神家園的論述, 其實清楚的指明了這 一點,批判性借鑒人類共有物質精神文明,才能實現多元化的百花齊放和百家爭鳴。

\section{（二）顯、隱性思政與英語聽說課程}

新時代思政課要堅持理直氣壯地進行公開、直接的顯性思政。總書記的重要論述揭示了思想政治理論 課教育教學的客觀規律, 是辦好新時代思政課的基本遵循。顯性思政需要教師重新認識、梳理、發掘英語課 程內容; 根據教學的內容, 因時、因地、因材地將思政元素有機融人到實踐教學之中。比如加人總理新聞發 佈會中的中英文交替接續翻譯, 不僅可以得到口語口譯的標準答案, 也可以收穫中國領導人的權威聲音與 嚴正態度。中英文雙語紀錄片材料的互相比較, 用最簡單和直白的對比來獲得英語聽說課程的工具性, 同 時也收穫紀錄片的人文性與社會科學的實驗精神。通過有具體價值觀靶向的學習材料, 將英語語言的實用 功能, 語言基礎知識和翻譯實戰技能, 在實實在在明明白白的文化與價值觀對比 (學習實踐)中, 收穫語言技 能也收穫直觀的思政進步。

思政課的隱性教育: 英語聽說課程思政不是要把思政課的內容簡單照搬到其他課程中, 不是專業課的 “思政化”, 生搬硬套往往照貓畫虎四不像。鑒於聽說課的技能性,直接的思政, 極其容易被貼上說教和口號 標籤。英語專業的隱形思政更多要從具備人文性深度的材料人手, 從文學性角度出發, 文學文本的多義性 以及修辭中的隱喻, 都是英語課程隱形思政的良好場域。聽說課程裏面的演講 (修辞) 和讋論 (口语思辨), 以及聽力材料中的文學性較強的歷史遺產片或者是大學公開課系列, 都是很好的批判性學習的工具和思政 二次再造的好材料。隱形思政的好處就在於, 它提供了新鮮和直觀的原材料, 也提供了可以批判性學習的 思維訓練契機。真理如果不是越辝越明的話, 那一定是偏聽偏信。思考讋論不僅僅是技能層面的訓練, 結 合文學性思想性強的材料,更能實現思維與三觀的綜合提升。

\section{二、課程多維度目標下的契合與新媒體演化助力}

思政教學的具體實現路徑,並不是喊口號和舉胳膊就可以實現。聽說課程教學的實踐路徑依賴: 課程 思政的課程設計理念、課程思政的教育理念, 教材改進和演化、以及教學素材的思政化和教學環節過程的潛 移默化。新媒體環境下, 聽說課程正面臨重生和再造的挑戰。

隨著學科核心素養的引人, 教師的教學理念逐步發生了改變: 不斷(终生) 學習、實踐教學、核心素養、全 方位育人等觀念深人人心, 學科思政教育的地位也隨之凸顯。英語聽說課程的教學目標越發顯得多維: 語 言技能工具性、口譯聽記培養目標、情感目標等都是重點。網路化智能化學習在英語教育領域, 有充分的技 術優勢: 英語自主學習、課堂教育能夠從局限的課堂延伸到課外, 使其在時空上更加自由化。傳統課堂內顯 性的、可控的英語專業技能更多的被凸顯, 而背後的文學性、思想性目標, 就成為問題的另一面一一在缺乏 傳統教育面授心傳的時候, 過度智能機器化的弊端, 使得思政和人文修養以及文學性可能會成為教育的缺 失薄弱的一環。

\section{（一）新媒体引发:教学教材革命与需要与时俱进思政的契合}

常態課程思政與應時應急課程思政的契合 ${ }^{(1)}$, 是一個可以辯證統一的問題。一方面思政的內容有賴於 
經典性, 意思就是一些長遠恒久的價值不會輕易變更; 另一方面則是, 思政有與時俱進的變革需要。聽說材 料的時效性和新媒體傳播形式的變革, 是其與時俱進最直接、直白的原因。外語專業的教學內容通常有兩 個特徵: 一個是以教材為主, 紙質媒體, 因為出版印刷周轉期長和改版困難, 通常有 “過去時” 的特徵; 綜英、 高英教材甚至有幾十年不變的情況。而校外機構往往是不斷革新教材,並不時往培訓教材裏面投人成功學 和人生心靈雞湯的私貨, 以便包裝出時髦和先進的味道; 逐利的本性也促使它們, 若有若無的在這些方面進 行思政 (洗脑)。另一方面, 先鋒的外語老師們也經常補充新鮮的外語視聽材料, 以便跟隨這些免費生鮮的 語言文化素材保持語言的活力, 通常有 “進行時”特徵。紙質教材的舊媒體形式, 常常不能日日革新, 缺乏有 效新媒體內容和形式的創新,連累思政也受制於媒體形式和內容。教學材料改進不夠及時, 缺乏時代性強 的當代思政材料,素材更新、思政更新未能齊頭並進和與時俱進。當代世界思想、哲學思潮、思政,往往風起 雲湧每隔數年 (竞选周期或是社科学派周期等), 就發生變化, 且有越來越快的趨勢。大量材料來源如 $\mathrm{BBC}$ 、 CNN、VOA 等等西方媒體,其媒體機構夾雜著政商利益,本身在西方就充滿爭議。其政黨輪換和利益團體的 相互衝突和妥協, 使得世界各種真假資訊, 常常被媒體放大、扭曲、甚至生造所謂事實; 其本身也飽受批判, 需要理性、耐心辨別真偽。

\section{（二）全媒體融合與思政學習的契合}

新媒體的融合經常需要文字與口語表達以及視頻全媒體融合的方式進行綜合表述。聽力和口語本是 單獨的技能訓練, 但隨著教學水準層次的提高, 課程的打通和融合日趨常見, 甚至連閱讀和寫作發展為讀後 學寫, 批判性寫作往往包含了閱讀後經驗, 其也益漸成為四六級考試, 專四考試等語言類考試的常見形式。 在視、聽、說、翻譯後,接續文化對比課程,這都是在新媒體下,技能、課程融合的典型範例; 其後是高年級文 化、文學課程的登場,大量富有文學文化底蘊的材料構建了一個個語義場,需要大量的課程建設,投人到新 視聽說材料的解讀,其時效性和應用性因此存在問題。教材的更新換代,紙質出版, 至少是以三兩年一個的 週期; 而視聽說材料的時效性可能只有半年到一年, 新聞英語及其話題的語言技能訓練價值可能隔年則如 隔山般古老。如 “弗洛伊德黑命貴” 新聞, 其背後的族群衝突和種族歧視問題, 需要借助深刻的文學性, 和國 際人文眼光, 來推動思政的與時俱進。

\section{（三）知識點碎片化與慕課課程系統化 ${ }^{2}$}

知識碎片化: 碎片化學習本身是網路慕課的一個特點, 也是學習的一種焦慮, 缺乏系統性和體系完整性 也是其先天不足特徵。但其開放式的課程特點, 給與了課程無限的擴充和升級的可能性。思政内容也可助 網路滲透進教學過程與內容,並與原來的碎片化知識點和課程素材重新整合, 構成新的教學與思政工作體 系。而不是依賴紙質教材的長週期出版和終極式的革新。

課程的系統化: 網路慕課以及資訊化課程資源的出現, 在某種程度上可以緩解碎片化的焦慮。新媒體 時代,教材教程的定義可能要更廣泛定義為包含電子出版物、電子網路課程、以及應用性軟體 APP 的綜合 體。一門專業課程,至少應該是有穂富理論和實踐經驗的老師,一本或多本處於經常更新狀態的教科書體 系, 以及一門經常得到學習者互動和更新的網路課程。紙質版的經典教材,作為傳統媒體的拜物主義觀念 下的神器, 是教師進行教學活動的主要依據, 是學生獲取知識的主要來源。其傳統屬性一直和傳統課堂一 起, 英語教師可以深人研究教材, 挖掘其中的德育因素, 設計合理的教學方案, 將其融人教學實踐, 將語言知 
Asia-Pacific Journal of Humanities and Social Sciences

識傳授與價值觀引領有機結合,更好地實現英語教學的目標。

\section{三、英語聽說課程目標與思政契合的實現路徑}

英語聽說課程目標的分支節點與以下有關: 文學性視聽材料的昇華、雙向的國際文化互動 (平衡性输人 输出）、顯隱性思政教學、實戰檢驗性課堂等有關。外語專業課程可從培養方案人手、教材建設為重點、資源 庫建設考試題庫建設為輔、課堂輸人輸出為重中之重, 構建外語專業課程思政實施體系, 目的當然是培飬具 備國際視野和中國情懷的跨文化交際專業人才。拿納稅人的錢培養接受高等教育的優秀公民,期待他們為 國家人民服務,這件事情其實一點也不意外, 又紅又專本身也並無問題。很多國家對於愛國的“顏色”定義 不一樣:有些國家和地區的綠色代表政治正確環保和平,有些則是藍色之類代表團結統一大同理想之類。

\section{（一）文學性材料與思政目標的契合與昇華}

選擇大學慕課、公開課課程裏的文學專題,避免應試類型材料的碎片化和片段化不完整學習;利用有文 學性和深刻思考的網路視聽材料,可以虛擬一個全英文的文學課堂和再造聽說學習空間。聽說課程可以借 此,進行高層次的口語和聽力練習。如文學文本研討式學習, 主題䛨論等, 以期昇華到有文學背景的三觀的 塑造上去, 期待進一步的批判性思維的引發。為了使課程知識與課程思政能夠在教學中有機融合、互為支 撐,保證思政素材的完整性和系統性:我們選取的教學材料為 BBC 所拍攝的以中國改革開放為主題的紀錄 片, 單集 13 分鐘, 集中講述改革開放的某個側面, 共 5 集。其材料因為是對於國家大事的宏觀描述, 其語言 使用往往規範且謹慎, 接近於口頭表達的 “雅言” 層次。也選用了《英國國家史》一類的歷史遺產片, 這種單 集 40 分鐘,總時長 15 集 600 分鐘的材料,保證了語言輸人的原文原材料真實性和權威性; 同時兼顧適當的 文學性口語雅言的出現。前者語速適中,無生僻單詞,適合大學生初學者學習。而歷史紀錄片則按照“歷史 回顧一文學背景一歷史脈絡一關聯未來” 的框架來依次展開,這些內容無疑是能夠達成我們所期盼的課程 思政的教學目標的為將思政引人課堂。尤其是《英國國家史》, 涉及到古英語和古代英國歷史, 以及現代英 語; 其體例和牛津字典類似, 言語中經常加人歷史文獻、以及文學典故作為佐證材料; 其目的也無非是想在 說文解字的過程中, 實現 “不學詩、無以言” 的修辭命題; 其實背後肯定還是要文以載道的。長期性的聽說學 習過程中, 加人有目的性的文學和思政材料, 有助於形成比較穩定長期可靠的人文觀念。同時也能對於西 方主流文明價值觀, 有一個前後一貫的主線的穩定把握。防止因為媒體、主持人的頻繁切換,被所謂小報紙 小媒體的偏見所輕易左右和顛覆既有主流觀點。

\section{（二）聽說課堂的思政輸入與思政輸出}

聽說課堂的技能訓練目標, 需要將輸入輸出來均衡發展: 語言技能上從口語、聽力技能以及口譯複合聽 說技能方面, 可以分為記憶、復述或交替傳譯、思辨探究等 ${ }^{3}$ 。使學生學會用英語恰當地表達中國文化, 傳達 中國思想文化和價值理念, 將所學應用於英語語境中, 實現知識學習、技能訓練、跨文化與價值觀教育的有 機融合, 進一步加深對英語語言的認知。聽說課堂教學, 其本身就是一個思政教育平臺, 應當被充分利用挖 掘課程中的思政元素, 發揮聽說課程領先帶動其他課程的優勢, 充分發揮各門課程的育人功能。聽說課程 作為載體, 可以顯性的採用思政教材與理念, 有針對性的進行選修課程的搭建。外國語語言和文學專業, 不 
僅僅是語言技能聽說讀寫譯的單一訓練的專業, 也是有文學文化課程作為底藴研習的專業。在實際的英語 聽說教學過程中, 為了保證語言輸人的真實性和連續性, 為學生營造原汁原味的語言環境, 原版引進的英語 教材備受推崇, 而本土化教材在編纂時, 也往往選擇國外的源語言材料,這樣做的結果就是學生在無形中受 到西方價值觀的滲透和隱性輸人, 導致中國文化、價值觀的缺失。同時, 因為文學材料過於圥長, 常常不能 完全消化,而導致。政治類文本的翻譯,是建立在基礎學習之上的; 中國文化在世界範圍内具有普世認同價 值,需要雙向溝通。兩會新聞發佈會材料具備了雙重價值,不僅有標準的中英文語言範本意義,也有思政和 國家價值觀的範本意義。也是極有雙向檢驗意義的翻譯口譯實戰檢驗材料。教師可以自主選編聽說教學 素材,將原教材與自選時事資料有機結合, 貼近社會現實的素材更容易激發學習興趣、產生情感共鳴,有助 於取得好的教學效果。一些新時代的主題,如: 中國文化、中國外交、新發展理念、人類命運共同體、一帶一 路等, 都可以潤物無聲地滲透於教學內容中。針對西方媒體資源, 教師需引導學生批判的汲取西方思想與 文化理念, 注意引領正確的價值取向, 培養學生的價值判斷能力。

\section{（三）國際文化思政雙向互動的契合}

學好外語的目標: 應該不止於單向輸人西方文化, 以及轉述解讀西方文化; 也包括為世界講好中國故 事, 傳遞中國聲音, 推動中華優秀傳統文化創造性轉化、創新性發展, 為人民提供精神指引。引導學生逐步 確立馬克思主義信仰, 堅定理想信念。外語專業是文化與意識形態安全的最前沿, 其專業屬性、育人功能、 人才培養目標決定了加強外語專業課程思政建設的必要性。

雙向互動實例: 英語聽說課程教學中,可以使用與教學内容相關的介紹中國文化、政治、經濟、風俗的英 語語音、視頻作為課堂或者課後訓練材料,提升學生對母語文化的認同感,提高學生用英語表述中國文化的 能力。比如美國的科羅拉多大峽谷和張家界為姊妹城市, 地形地貌和公園風景文化的營造, 有著極大的相 似性。兩邊都有紀錄片,完全可以先選擇以美國國家地理材料作為聽力輸人,其後選擇中文版本的張家界 紀錄片作為口譯和筆譯實踐,強化剛剛輸人的辭彙以及巨型。在思政層面可以比較兩個國家公園景點,對 於當地土著文化、民族文化的開發與保護。深刻的認識到吉首大學張家界校區外國語學院, 在當地旅遊文 化以及文旅扶貧方面的重要地位。

\section{（四）文化翻譯對等的選擇}

雖然聽說課只是涉及到語言文化層面比較直白和淺顯的東西, 但作為文化翻譯 (口译) 層面的導人, 卻 是很有意義。典籍翻譯中的對等, 首要的是文本層次的對等, 其後才會有翻譯功能以及形式方面的對等發 生。《道德經》、《論語》等中文典籍, 在被西方傳教士初譯為英文版的時候, 也參考了《聖經》等西方經典的 原文和中文譯本, 意思就是要建立一個文化橋樑, 方便雙向互通。要是沒有互通的話, 此種文化價值就只能 是單向和不能經歷普世考驗的。早期的人類語錄體典籍、宗教書籍, 大都有關於人生意義的終極思考一類: 馬太福音中的“虛空”, 言語即道本身, 對應《道德經》中的道生萬物、道本道無常道之類, 其實都可以譯介互 通。至於文化選擇, 智者樂水, 仁者樂山。

除了紐約時報、華盛頓郵報、經濟學家等西方經典報刊,教師還應該引導學生堅持閱讀 China Daily (中 国日报）、Beijing Review一類英文報刊, 堅持收聽、收看 CCTV 的系列英文頻道。閱讀 The Analects of Confucius (《论语》) 等中文古典著作; 以及經典性可以相對應的英文版經典著作。精神上也可以將李白詩句延 
續了夫子以及《楚辭》中的浪漫精神: “我本楚狂人, 鳳歌笑孔丘”; 對照西方革命派的“No king, No king”, 以 及各種後現代的搖滾解構: “we are the world, we are the champions”。引導學生合理利用新媒體,好的學習平 臺更好地瞭解國家, 瞭解家鄉民風民情,樹立好文化自信。“講好中國故事、傳播好中國聲音、闡釋好中國特 色、展示好中國形象”。弘揚傳統文化, 堅定文化自信, 建立中國文化經典與西方文化經典,在思政上的交流 機制, 而不僅僅是做排除法的選擇題。

\section{結語}

課程思政在教材、教學資源中、以及教學活動中的滲透與效果的實現,其效果量化與評估是一個需要耐 心和時間的難題。課程思政本身是一個融人性活動, 它的效果無法再短短數日内就能測評得到 ${ }^{4}$ 。傳統的 語言測試評估需要修正方法,複合以情感因素調查法等綜合方法才能初步測探課程思政效果。可能更長的 時間維度,更宏觀的課程規劃,更細緻的教學方案,才有可能達到春風化雨的效果。

\section{注釋}

(1) 陳脌:《高校外語專業課程思政的實施理路》,《思想理論教育》2021 年版。

(2) 李良嘉: 《微課支架下英語聽說課程的網絡化學習多模態》, 《中文學刊》2 021 年第 2 期。

(3) 王靘:《課程思政」理念下英語口譯混合式教學實践探索》,《教育與考試》2020 年第 6 期。

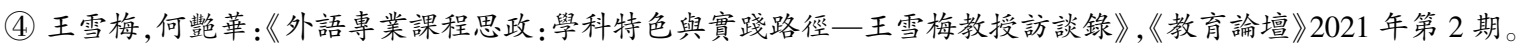

